\title{
LAMINAR NATURAL CONVECTION OF NON-NEWTONIAN NANOFLUIDS IN A SQUARE ENCLOSURE WITH DIFFERENTIALLY HEATED SIDE WALLS
}

\author{
Ternik, P.* \& Rudolf, R. ${ }^{* * * * *}$ \\ ${ }^{*}$ Ternik Primož - Private Researcher, Bresterniška ulica 163, 2354 Bresternica, Slovenia \\ ** University of Maribor, Faculty of Mechanical Engineering, Smetanova 17, 2000 Maribor, Slovenia \\ *** Zlatarna Celje d.d., Kersnikova ulica19, 3000 Celje, Slovenia \\ E-Mail: pternik@pt-rtd.eu, rebeka.rudolf@um.si
}

\begin{abstract}
The present work deals with the laminar natural convection in a square cavity with differentially heated side walls subjected to constant temperatures and filled with homogenous 0,4 wt. \% aqueous solution of carboxymethyl cellulose (CMC) based $\mathrm{Au}, \mathrm{Al}_{2} \mathrm{O}_{3}$, $\mathrm{Cu}$ and $\mathrm{TiO}_{2}$ nanofluids obeying the Power law rheological model. The governing differential equations have been solved by the standard finite volume method and the hydrodynamic and thermal fields are coupled together using the Boussinesq approximation.

The main objective of this study is to investigate the influence of the nanoparticles' volume fraction $(0 \% \leq \varphi \leq 10 \%)$ on the heat transfer characteristics of CMC based nanofluids over a wide range of nanofluid Rayleigh number $\left(10^{3} \leq R a_{n f} \leq 10^{6}\right)$.

Accurate numerical results are presented in the form of dimensionless temperature and velocity variations, isotherms, mean Nusselt number and heat transfer enhancement. The results indicate clearly that the heat and momentum transfer characteristics are affected only by the nanofluid Rayleigh number, while the type of nanoparticles (i.e. thermo-phyisical properties) and their volume fraction have effect only on the heat transfer enhancement.

(Received in December 2011, accepted in October 2012. This paper was with the authors 3 months for 1 revision.)
\end{abstract}

Key Words: Natural Convection, Non-Newtonian Nanofluids, Mean Nusselt Number, Heat Transfer Rate Enhancement, Numerical Modelling

\section{INTRODUCTION}

Today more than ever, ultrahigh-performance and controlled heat transfer plays an important role in the development of energy-efficient heat transfer systems and fluids which are required in many industries and commercial applications [1-3]. However, conventional heat transfer fluids (e.g. water, oil or ethylene glycol) are inherently poor heat transfer fluids. For that, nano-sized particles dispersed in a base fluid, known as nanofluid [4], have been developed, used and researched extensively to enhance heat transfer. The presence of nanoparticles shows an unquestionable heat transfer enhancement in forced convection applications. But on the other hand, there is still a dispute on the role of nanoparticles on the heat transfer for the buoyancy driven flow.

Natural convection (i.e. flow caused by the temperature induced density variations) is one of the most extensively analysed configurations because of its fundamental importance as the "benchmark" problem to study convection effects (and compare as well as validate numerical techniques). In addition to the obvious academic interest, this configuration has relevance in various engineering systems (e.g. compact heat exchangers [5] and cooling systems [6, 7], selective laser melting process [8]). Although quite some various different configurations of 
the enclosure problem are possible, one of the most studied cases involves the twodimensional square enclosure with differentially heated isothermal vertical walls and adiabatic horizontal walls. When the vertical walls are insulated to ensure adiabatic conditions and the lower horizontal wall held at the higher temperature then one has the classical Rayleigh-Bénard configuration.

The present study analyses the case where the horizontal walls are adiabatic and the temperature difference driving the convection comes from the sidewalls as in the classic benchmark paper of de Vahl Davis [9]. Although this configuration has been studied extensively for Newtonian fluids, a much smaller amount of information is available for the nanofluids. Most of the researchers have been focused on numerical modelling of buoyancy induced flows of Newtonian (mainly water-based) nanofluids. Recent numerical studies by Ternik et al. [10], Ternik and Rudolf [11], Oztop et al. [12] and Abu-Nada and Oztop [13] illustrated that nanoparticles suspended in Newtonian base fluid substantially enhance the heat transfer for any given Rayleigh number.

On the other hand, even less research work have been conducted if the rheological behaviour of nanofluid is more complex (i.e. the relationship between the shear stress and shear rate is non-linear). Natural convection heat transfer of non-Newtonian nanofluids (dispersion of $\mathrm{Al}_{2} \mathrm{O}_{3}$ and $\mathrm{TiO}_{2}$ nanoparticles in a $0,5 \mathrm{wt} . \%$ aqueous solution of carboxymethyl cellulose) in a vertical cylinder uniformly heated from below and cooled from top was investigated experimentally by Mahrood et al. [14]. They showed that the heat transfer performance of nanofluids is significantly enhanced at low particle concentrations and that increasing nanoparticle concentration has a contrary effect on the heat transfer of nanofluids. Cheng [15] studied the free convection heat transfer over a truncated cone embedded in a porous medium saturated by a non-Newtonian power-law nanofluid with constant wall temperature and constant wall nanoparticle volume fraction and reported that increasing the thermophoresis parameter or the Brownian parameter tends to decrease the reduced Nusselt number. Forced convective heat transfer effect on the non-Newtonian nanofluid (containing $\mathrm{Al}_{2} \mathrm{O}_{3}$ and Xanthan aqueous solution as a liquid single phase) flow in the horizontal tube with constant heat flux was numerically investigated by Moraveji et al. [16]. Their results showed that heat transfer coefficient and Nusselt number of non-Newtonian nanofluid increased with increasing concentration of Xanthan solution.

The above review of the existing literature shows that the problem of natural convection in a square enclosure filled with a non-Newtonian nanofluid is an issue still far from being completely solved. Framed in this general background, the purpose of the present study is to examine the effect of adding $\mathrm{Al}_{2} \mathrm{O}_{3}, \mathrm{Au}, \mathrm{Cu}$ and $\mathrm{TiO}_{2}$ nanoparticles to the base fluid (which exhibits non-Newtonian viscous behaviour) on the heat and momentum transfer characteristics in a square cavity with differentially heated vertical and adiabatic horizontal walls over the range of the nanofluid Rayleigh number and volume fraction.

The rest of the paper is organised as follows. The necessary mathematical background and numerical details are presented in Section 2 which is followed by the grid refinement, numerical accuracy assessment and validation study (Section 3). Following this analysis, the results are presented and subsequently discussed (Section 4). The main findings are summarised and conclusions are drawn in the final section of this paper.

\section{NUMERICAL MODELLING}

The standard finite volume method (successfully used in numerical studies of isothermal [17] and non-isothermal $[10,11]$ generalized Newtonian fluid flows) is used to solve the coupled conservation equations of mass, momentum and energy. In the present framework, the second-order central differencing scheme is used for the diffusive terms and the second-order 
Higher upwind scheme for the convective terms. The convergence criteria were set to $10^{-9}$ for all the relative (scaled) residuals.

\subsection{Governing equations}

For the present study steady-state flow of an incompressible CMC based nanofluids is considered. It is assumed that the fluid phase and nanoparticles are in both, thermal and chemical equilibrium. Except for the density the properties of nanoparticles and fluid are taken to be constant. Table I presents the thermo-physical properties of CMC and Au nanoparticles at the reference temperature. It is further assumed that the Boussinesq approximation is valid for the buoyancy force.

Table I: Thermo-physical properties of nanofluids.

\begin{tabular}{|l|c|c|c|c|}
\cline { 2 - 5 } \multicolumn{1}{c|}{} & $\rho\left[\mathrm{kg} / \mathrm{m}^{3}\right]$ & $c_{p}[\mathrm{~J} / \mathrm{kgK}]$ & $k[\mathrm{~W} / \mathrm{mK}]$ & $\beta[1 / \mathrm{K}]$ \\
\hline $0,4 \% \mathrm{CMC}$ & 997,1 & 4179 & 0,613 & $2,1 \times 10^{-4}$ \\
\hline $\mathrm{Au}$ & 19320 & 128,8 & 314,4 & $1,416 \times 10^{-7}$ \\
\hline $\mathrm{Al}_{2} \mathrm{O}_{3}$ & 3970 & 765 & 40 & $8,5 \times 10^{-6}$ \\
\hline $\mathrm{Cu}$ & 8933 & 385 & 400 & $1,67 \times 10^{-5}$ \\
\hline $\mathrm{TiO}_{2}$ & 4250 & 686,2 & 8,9538 & $9,0 \times 10^{-6}$ \\
\hline
\end{tabular}

The governing equations (mass, momentum and energy conservation) for a steady, laminar and incompressible flow are:

$$
\begin{gathered}
\frac{\partial v_{i}}{\partial x_{i}}=0 \\
\rho_{n f} v_{j} \frac{\partial v_{i}}{\partial x_{j}}-\frac{\partial}{\partial x_{j}}\left[\eta_{n f}(|\dot{\gamma}|) \frac{\partial v_{i}}{\partial x_{j}}\right]=-\frac{\partial p}{\partial x_{i}}+(\rho \beta)_{n f} g\left(T-T_{C}\right)+\frac{\partial}{\partial x_{j}}\left[\eta_{n f}(|\dot{\gamma}|) \frac{\partial v_{j}}{\partial x_{i}}\right] \\
\left(\rho c_{p}\right)_{n f} v_{j} \frac{\partial T}{\partial x_{j}}=\frac{\partial}{\partial x_{j}}\left(k_{n f} \frac{\partial T}{\partial x_{j}}\right)
\end{gathered}
$$

In the momentum balance law (Eq. (2)) the constitutive (rheological) model is needed for the viscous function $\eta_{n f}(|\dot{\gamma}|)$. In the case of generalized Newtonian fluids, the form of the general relationship between the shear stress and shear rate is:

$$
\tau_{i j}=\eta_{n f}(|\dot{\gamma}|) \dot{\gamma}_{i j}
$$

where $|\dot{\gamma}|=\sqrt{(1 / 2) \sum_{i} \sum_{j} \dot{\gamma}_{i j} \dot{\gamma}_{j i}}$ is the II. invariant of the symmetrical rate of deformation tensor with Cartesian components $\dot{\gamma}_{i j}=\left(\partial v_{i} / \partial x_{j}\right)+\left(\partial v_{j} / \partial x_{i}\right)$. Based on Eq. (4), the viscous function for the Power law (i.e. Ostwald-de Waele) rheological model is:

$$
\eta_{n f}(|\dot{\gamma}|)=K|\dot{\gamma}|^{n-1}
$$

where $K$ is the consistency and $n$ is the dimensionless Power law index with experimentally determined values (for 0,4 \% aqueous CMC solution) $K=0,048 \mathrm{Pas}^{n}$ and $n=0,882$.

Relationships between properties of nanofluid ( $n f)$ to those of base fluid $(b f)$ and pure solid (s) are given with the following empirical models [10, 11, 13]:

- Density: $\quad \rho_{n f}=(1-\varphi) \rho_{b f}+\varphi \rho_{s}$ 
- Dynamic viscosity: $\quad \eta_{n f}=\eta_{b f} /(1-\varphi)^{2.5}$

- Thermal expansion: $\quad(\rho \beta)_{n f}=(1-\varphi)(\rho \beta)_{b f}+\varphi(\rho \beta)_{s}$

- Heat capacitance: $\quad\left(\rho c_{p}\right)_{n f}=(1-\varphi)\left(\rho c_{p}\right)_{b f}+\varphi\left(\rho c_{p}\right)_{s}$

- Thermal conductivity: $k_{n f}=k_{b f} \frac{k_{s}+2 k_{b f}-2 \varphi\left(k_{b f}-k_{s}\right)}{k_{s}+2 k_{b f}+\varphi\left(k_{b f}-k_{s}\right)}$

\subsection{Geometry and boundary conditions}

The simulation domain and the expected temperature distribution are shown schematically in Fig. 1. Two vertical walls of a square enclosure are kept at different constant temperatures $\left(T_{H}>T_{C}\right)$, whereas the other boundaries are considered to be adiabatic in nature. Both velocity components (i.e. $v_{x}$ and $v_{y}$ ) are identically zero on each boundary because of the no-slip condition and impenetrability of rigid boundaries. The temperatures for cold and hot vertical walls are specified $\left(T_{x=0}=T_{H}, T_{x=L}=T_{C}\right)$. The adiabatic temperature boundary conditions for the horizontal insulated boundaries are given by $\partial T / \partial y=0$ at $y=0$ and $y=L$.
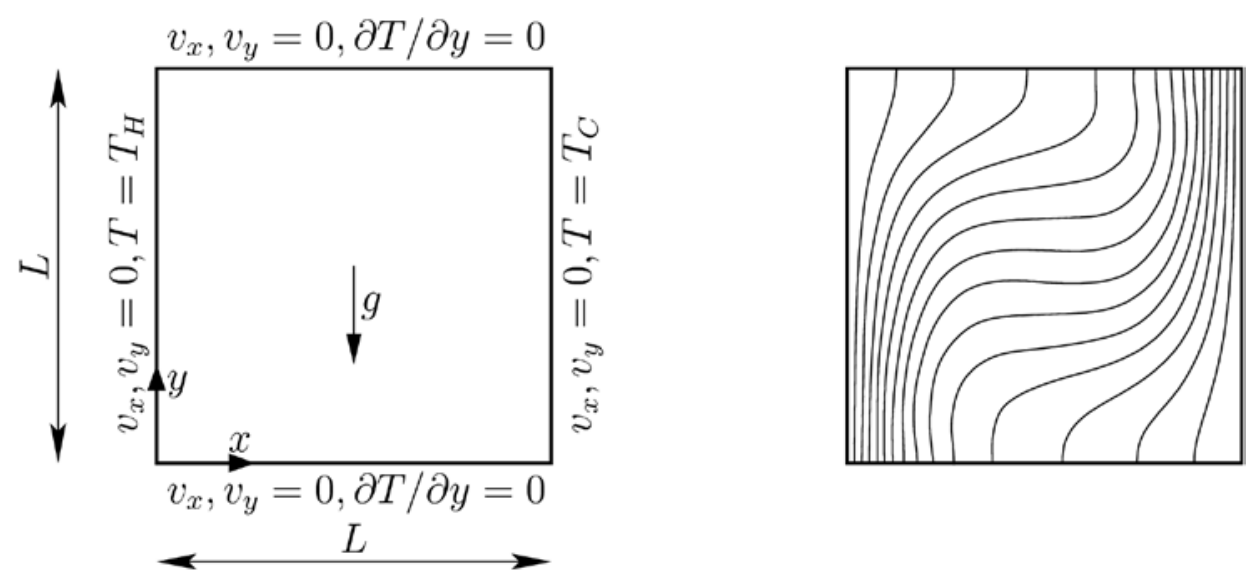

Figure 1: Simulation domain (left) and the expected temperature field (right).

In the present study, the heat transfer characteristics are presented (and compared for the same value of the nanofluid Rayleigh number) in terms of the mean Nusselt number:

$$
\overline{N u}=\int_{0}^{L} N u(y) d y / L
$$

and relative enhancement of the heat transfer rate between the nanofluid ( $n f$ ) and the base fluid (bf):

$$
E=\frac{Q_{n f}-Q_{b f}}{Q_{b f}} \times 100 \%=\left[\frac{k_{n f}}{k_{b f}} \frac{\overline{N u}_{n f}}{\overline{N u}_{b f}}-1\right] \times 100 \%
$$

where $Q_{n f}=k_{n f} \overline{N u}_{n f} A \Delta T / L$ and $Q_{b f}=k_{b f} \overline{N u}_{b f} A \Delta T / L$ are the heat transfer rates of nanofluid and base fluid. Here, the nanofluid Rayleigh number $R a_{n f}$ represents the ratio of the strengths of buoyant thermal transports to thermal diffusion and for the non-Newtonian Power-law nanofluids is expressed as $[18,19]$ :

$$
R a_{n f}=\frac{\rho_{n f}\left(\rho c_{p}\right)_{n f}^{n} g \beta_{n f} \Delta T L^{2 n+1}}{k_{n f}^{n} K}
$$


In order to investigate the influence of solid particles volume fraction $\varphi$ on the heat transfer characteristics (i.e. mean Nusselt number and heat transfer rate enhancement), the Prandtl number of CMC based Power-law nanofluids is defined $[18,19]$ :

$$
\operatorname{Pr}_{n f}=\frac{K}{\rho_{n f}}\left(\frac{k}{\rho c_{p}}\right)_{n f}^{n-2} L^{2-2 n}
$$

Using Eq. (9) we show (Fig. 2) that value of the nanofluid Prandtl number decreases as the volume fraction of nanoparticles in CMC base fluid increases and that for the investigated range of $\varphi$ its values are $P r_{n f}>>1$.

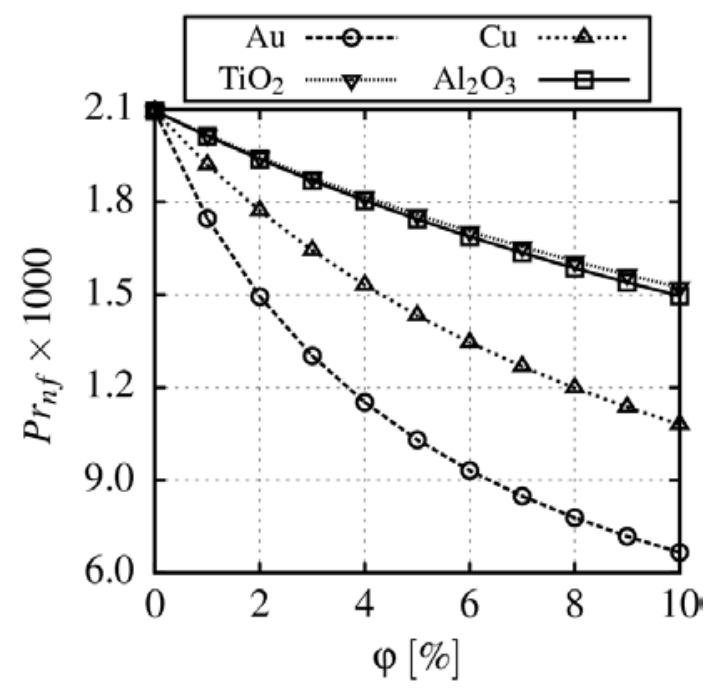

Figure 2: Variation of the nanofluid Prandtl number with the nanoparticles' volume fraction.

\section{GRID REFINEMENT, NUMERCAL ACCURACY AND VALIDATION}

The grid independence and numerical accuracy of the present results has been established on a detailed analysis using three different uniform meshes; MI(50×50), MII $(100 \times 100)$ and $\operatorname{MIII}(200 \times 200)$. With each grid refinement the number of elements in particular direction is doubled and element size is halved. Such a procedure is useful for applying the Richardson's extrapolation technique which is a method for obtaining a higher-order estimate of the flow value (value at infinite grid) from a series of lower-order discrete values [20].

For a general primitive variable $\phi$ the grid-converged (i.e. extrapolated to the zero element size) value according to Richardson extrapolation is given as:

$$
\phi_{\text {ext }}=\phi_{\text {MIII }}-\left(\phi_{\text {MII }}-\phi_{\text {MIII }}\right) /\left(r^{p}-1\right)
$$

where $\phi_{\text {MIII }}$ is obtained on the finest grid and $\phi_{M I I}$ is the solution based on next level of coarse grid, $r=2$ is the ratio between the coarse to fine grid spacing and $p=2$ is the order of convergence.

The variation of the mean Nusselt number $\overline{\mathrm{Nu}}$ with the grid refinement is provided in tabulated form in Table II. The "percent" numerical error for the mean Nusselt number:

$$
\text { Error }=\left|\left(\overline{N u}_{M I I I}-\overline{N u}_{e x t}\right) / \overline{N u}_{\text {ext }}\right| \times 100 \%
$$

as given in Table II is a quantification of the relative difference between the numerical predictions of $\overline{N u}$ on MIII and the extrapolated value $\overline{N u}_{\text {ext }}$ obtained from Richardson's extrapolation technique. It can be seen that the differences with grid refinement are exceedingly small and the agreement between mesh MIII and extrapolated value is extremely good; the discretisation error for $\overline{\mathrm{Nu}}$ is less than $0,3 \%$. 
Table II: Effect of mesh refinement upon the mean Nusselt number for CMC-Au nanofluid $\left(R a_{n f}=10^{5}, \varphi=10 \%\right)$.

\begin{tabular}{|c|c|c|c|c|c|}
\cline { 2 - 6 } \multicolumn{1}{c|}{} & $M I$ & MII & MIII & $\overline{N u}_{\text {ext }}$ & Error \\
\hline$\overline{\mathrm{Nu}}$ & 6,4705 & 6,2260 & 6,1725 & 6,1547 & 0,29 \\
\hline
\end{tabular}

In addition to the aforementioned grid-dependency study, the present simulation results have also been compared against the results of Turan et al. [18] for natural convection of the shear-thinning Power-law fluid. The comparisons between the present numerical results (obtained with mesh MIII) with the benchmark values (summarised in Table III) are extremely good and entirely consistent with our grid-dependency studies.

Table III: Comparison of the present results with the benchmark values $(n=0,80, \operatorname{Pr}=1000)$.

\begin{tabular}{|r|c|c|c|}
\cline { 2 - 4 } \multicolumn{1}{c|}{} & $\begin{array}{c}\mathrm{Ra}=10^{4} \\
\overline{\mathrm{Nu}}\end{array}$ & $\begin{array}{c}R a=10^{5} \\
\overline{N u}\end{array}$ & $\begin{array}{c}R a=10^{6} \\
\overline{N u}\end{array}$ \\
\hline Present study & 3,3601 & 7,6432 & 16,3943 \\
\hline Turan et al. [18] & 3,3595 & 7,6268 & 16,2643 \\
\hline
\end{tabular}

All these results and comparison with existing numerical data from the literature gave sufficient confidence in the present numerical procedure allowing us to proceed with simulations over the whole range of $R a_{n f}$ and $\varphi$. Accounting for numerical accuracy and number of elements mesh MIII was found to be a fair compromise and all results presented in continuation were obtained with this mesh.

\section{RESULTS AND DISCUSSION}

\subsection{Temperature and velocity flow field}
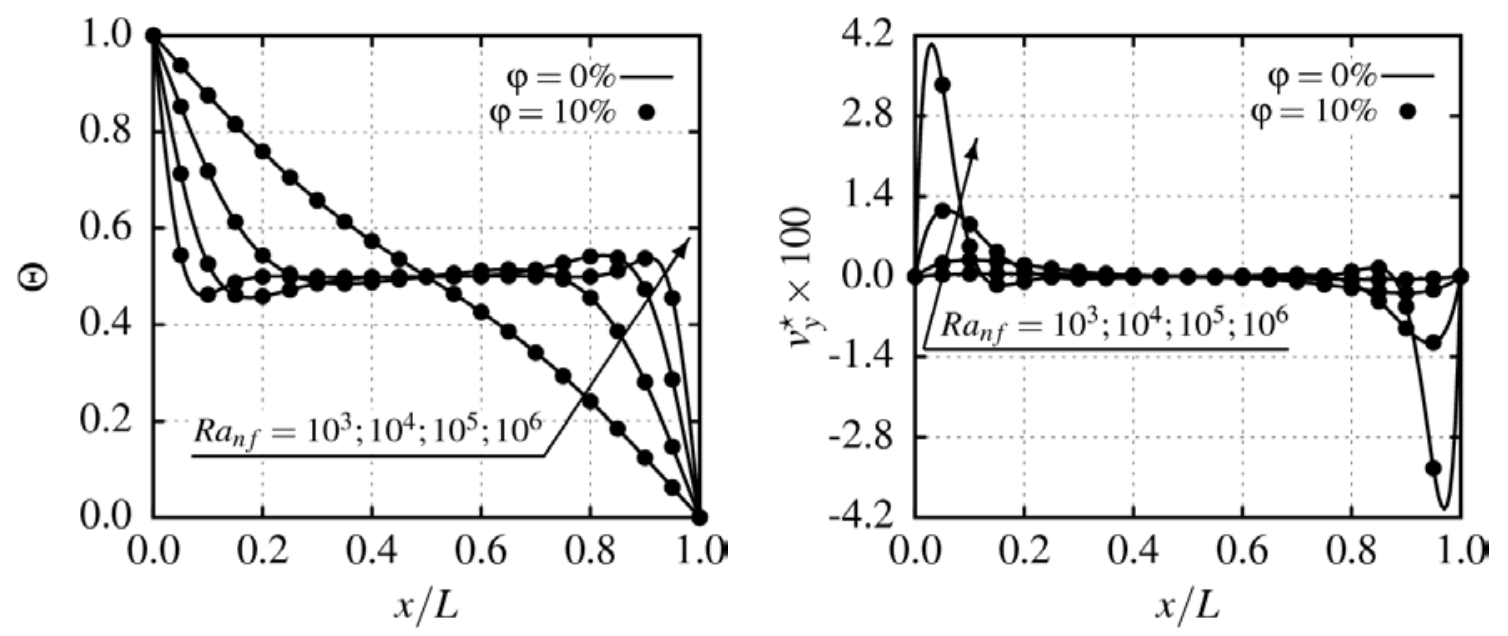

Figure 3: Variations of non-dimensional temperature $\theta$ (left) and non-dimensional vertical velocity component $v_{y}{ }^{*}$ (right) for CMC-Au nanofluid along the horizontal midplane $(y / L=0,50)$.

It is useful to inspect the distributions of dimensionless temperature $\theta=\left(T-T_{C}\right) /\left(T_{H}-T_{C}\right)$ and velocity $v_{y}^{*}=v_{y} L / \alpha_{n f}$ in order to understand the influences of 
$R a_{n f}$ and $\varphi$ on the heat transfer characteristics during natural convection of CMC-based nanofluids in the square enclosure. The distributions of $\theta$ and $v_{y}{ }^{*}$ along the horizontal midplane for CMC-Au nanofluid are shown in Fig. 3 for different values of $\varphi$.
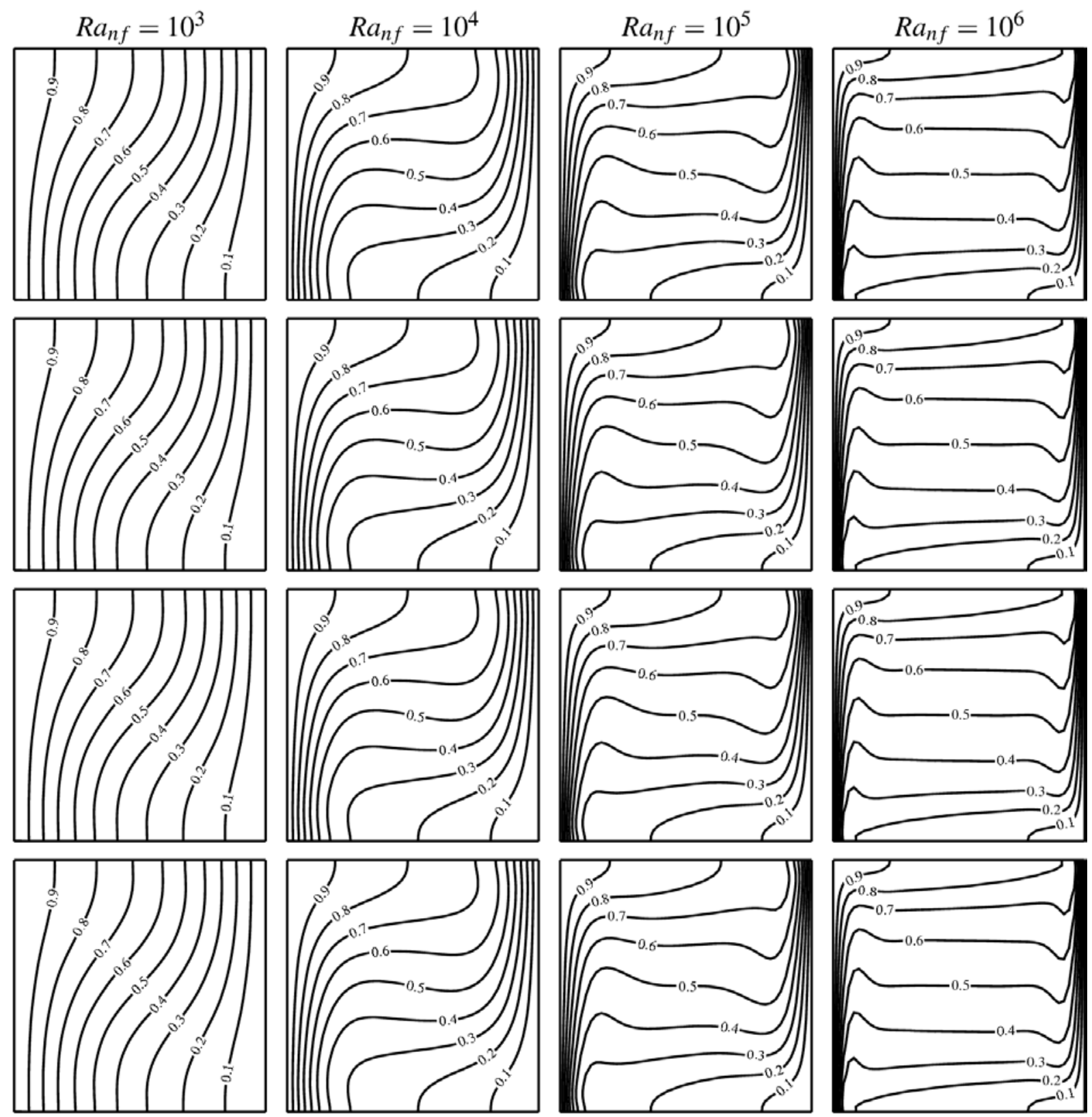

Figure 4: Contours of non-dimensional temperature $\theta$ for CMC-Au ( $\left.1^{\text {st }} \mathrm{row}\right), \mathrm{CMC}-\mathrm{Al}_{2} \mathrm{O}_{3}\left(2^{\text {nd }}\right.$ row $), \mathrm{CMC}-\mathrm{Cu}\left(3^{\text {rd }}\right.$ row $)$ and $\mathrm{CMC}-\mathrm{TiO}_{2}\left(4^{\text {th }}\right.$ row $)$ nanofluid for $\varphi=5 \%$.

It is evident from Fig. 3 (left) that the distributions of $\theta$ become increasing non-linear for increasing values of $R a_{n f}$. This statement is supported by the data plotted in Fig. 3 (right) which demonstrates that the magnitude of the velocity component increases significantly with increasing $R a_{n f}$. For a given set of values of $\varphi$ an increase in $R a_{n f}$ gives rise to strengthening of buoyancy forces in comparison to viscous forces which can be seen from Fig. 3 (right) where the magnitude of $v_{y}{ }^{*}$ increases with increasing $R a_{n f}$. As the convective transport strengthens with increasing $R a_{n f}$ the distribution of $\theta$ becomes significantly more non-linear with increasing $R a_{n f}$ (see the profiles in Fig. 3 (left)). At $R a_{n f}=10^{3}$ the distribution of $\theta$ is completely linear and the vertical velocity component $v_{y}{ }^{*}$ is essentially negligible due to very 
weak flow as the effects of buoyancy forces are dominated by viscous effects. Under this circumstance, the heat transfer takes place principally by conduction across the square enclosure. The effects of buoyancy force strengthens relative to the viscous force with increasing $R a_{n f}$, which in turn augments heat transfer by convection due to stronger buoyancydriven flow with higher vertical velocity magnitude. This effect is clearly evident from Fig. 3, which indicates that the vertical velocity magnitude does indeed increase with increasing $R a_{n f}$ and that the distribution of non-dimensional temperature becomes increasingly non-linear with strengthening of convective transport for higher values of $R a_{n f}$.

In addition, it is interesting to notice that heat and momentum characteristics at given $R a_{n f}$ are independent of the volume fraction $\varphi$ (see Fig. 3) and the type of nanoparticles (see Fig. 4). This finding is a reflection of the nanofluid Prandtl number values considered in the present study. Its value decreases with increasing $\varphi$ (as shown in Fig. 2) and for this range of $P r_{n f}$ values (i.e. $P r_{n f}>>1$ ) the hydrodynamic boundary layer thickness remains much greater than the thermal boundary layer thickness and as a result a change in $\varphi$ (and therefore in $P r_{n f}$ ) principally modifies the relative balance between viscous and buoyancy forces so the heat transport in the thermal boundary layer gets only marginally affected.

Fig. 4 shows that the effects of convection strengthen with increasing $R a_{n f}$ which is reflected in progressively curved isotherms for higher values of nanofluid Rayleigh number. It is clear from Fig. 4 that the thermal boundary layer thickness decreases with increasing $R a_{n f}$. As a results, the thinning of boundary layer thickness for larger values of $R a_{n f}$ acts as to enhance the magnitude of wall heat flux for the vertical walls, which gives rise to an increase in the mean Nusselt number.

\subsection{Mean Nusselt number}
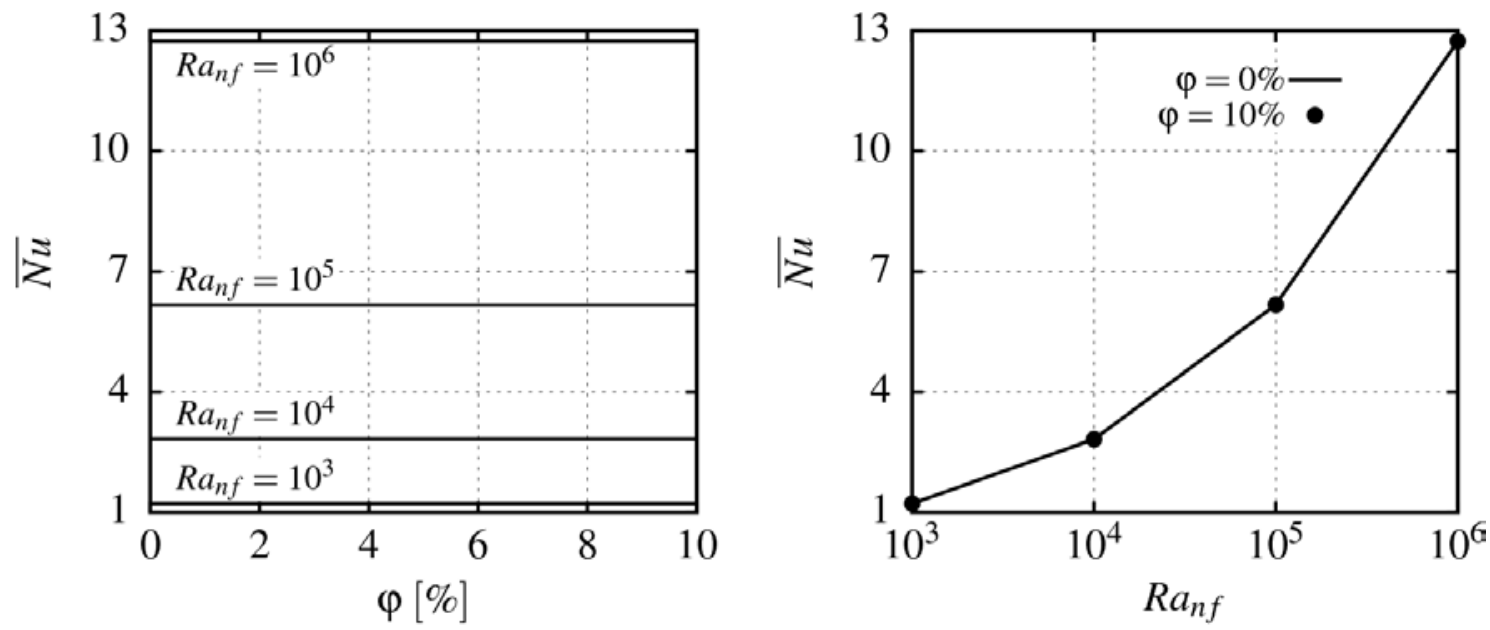

Figure 5: Variation of mean Nusselt number $\overline{\mathrm{Nu}}$ with volume fraction $\varphi$ (left) and nanofluid Rayleigh number $R a_{n f}$ (right) for CMC-Au nanofluid.

The variation of the mean Nusselt number $\overline{N u}$ with volume fraction $\varphi$ and nanofluid Rayleigh number $R a_{n f}$ for CMC-Au nanofluid is shown in Fig. 5 which indicates that $\overline{N u}$ increases monotonically with increasing $R a_{n f}$. Moreover, it is clear that the changes in the volume fraction $\varphi$ do not affect the distributions of $\theta$ and $v_{y}{ }^{*}$ (see Figs. 3 and 4) and therefore $\varphi$ (and consequently $P r_{n f}$ ) does not have a major influence on the value of $\overline{\mathrm{Nu}}$ in the range of volume fraction considered here. In addition, the same variations of $\overline{N u}$ with $\varphi$ and $R a_{n f}$ have been observed (but not shown due to the replication of results) for all CMC-based nanofluids (i.e. $\mathrm{Au}, \mathrm{Al}_{2} \mathrm{O}_{3}, \mathrm{Cu}$ and $\mathrm{TiO}_{2}$ ) considered in the present study. 

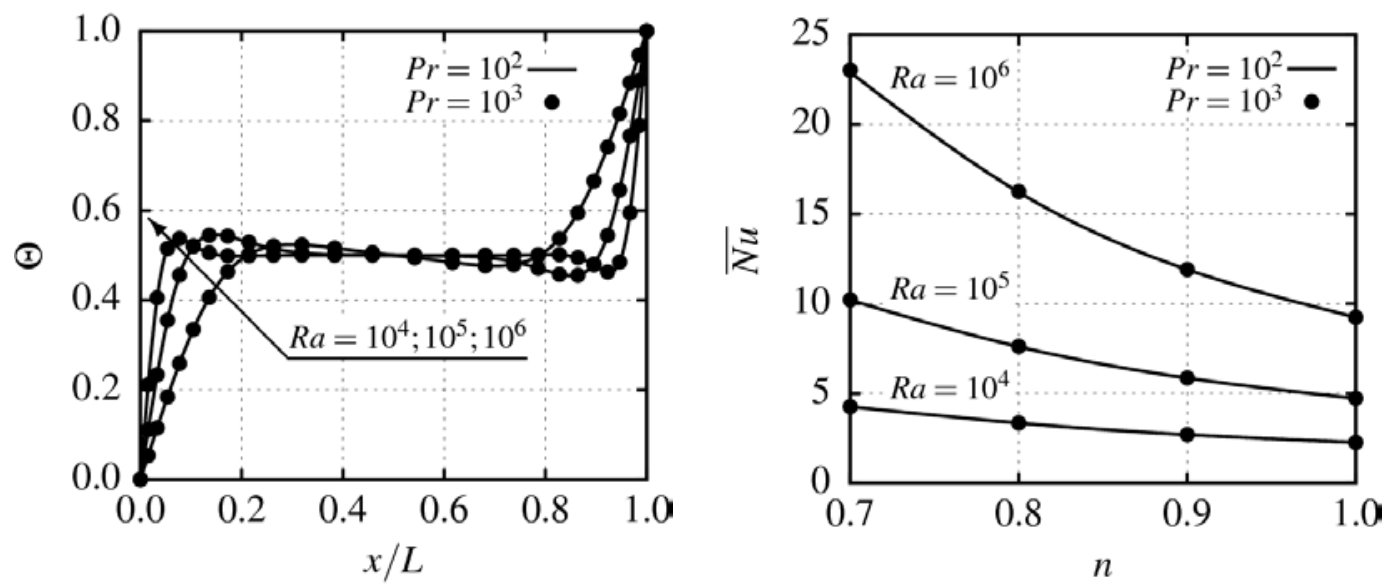

Figure 6: Variations of non-dimensional temperature $\theta$ along the horizontal mid-plane (left) and mean Nusselt number (right) for Power-law fluids [18].

Previous observations are consistent with earlier findings in the context of Newtonian as well as non-Newtonian Power-law fluids [18] which demonstrated negligible $\mathrm{Pr}$ dependence of $\theta$ and $\overline{\mathrm{Nu}}$ for $\operatorname{Pr}>1$ (Fig. 5). For large values of $\operatorname{Pr}$ the hydrodynamic boundary layer thickness remains much greater than the thermal boundary layer thickness thus the transport characteristics are primarily driven by buoyancy and viscous forces which is reflected in the weak Prandtl number dependence of $\overline{\mathrm{Nu}}$ for large values of $\mathrm{Pr}$.

\subsection{Heat transfer rate enhancement}

The relative enhancement of the heat transfer rate $E$ (as defined by Eq. (7)) is plotted with respect to the Au nanoparticles volume fraction $\varphi$ at two values (i.e. minimum and maximum) of the nanofluid Rayleigh number $R a_{n f}$ (Fig. 7 (left)) and to the volume fraction of all nanoparticles investigated in the present study (Figure 7 (right)). Considering the whole range of the nanofluid Rayleigh number, the Figure 7 (left) illustrates that the enhancement of the heat transfer rate increases with increasing $\varphi$, but is practically unaffected by the value of $R a_{n f}$. This is consistent with the fact that the ratio of the nanofluid and the base fluid mean Nusselt number $\overline{N u}_{n f} / \overline{N u}_{b f}=1$ remains constant for all values of the nanoparticles volume fraction $\varphi$ at given nanofluid Rayleigh number $R a_{n f}$ (see Fig. 5). As a result, the heat transfer rate enhancement is affected only by the ratio of the nanofluid to the base fluid thermal conductivity $k_{n f} / k_{b f}$, which increases with the increasing $\varphi$ (Fig. 8).
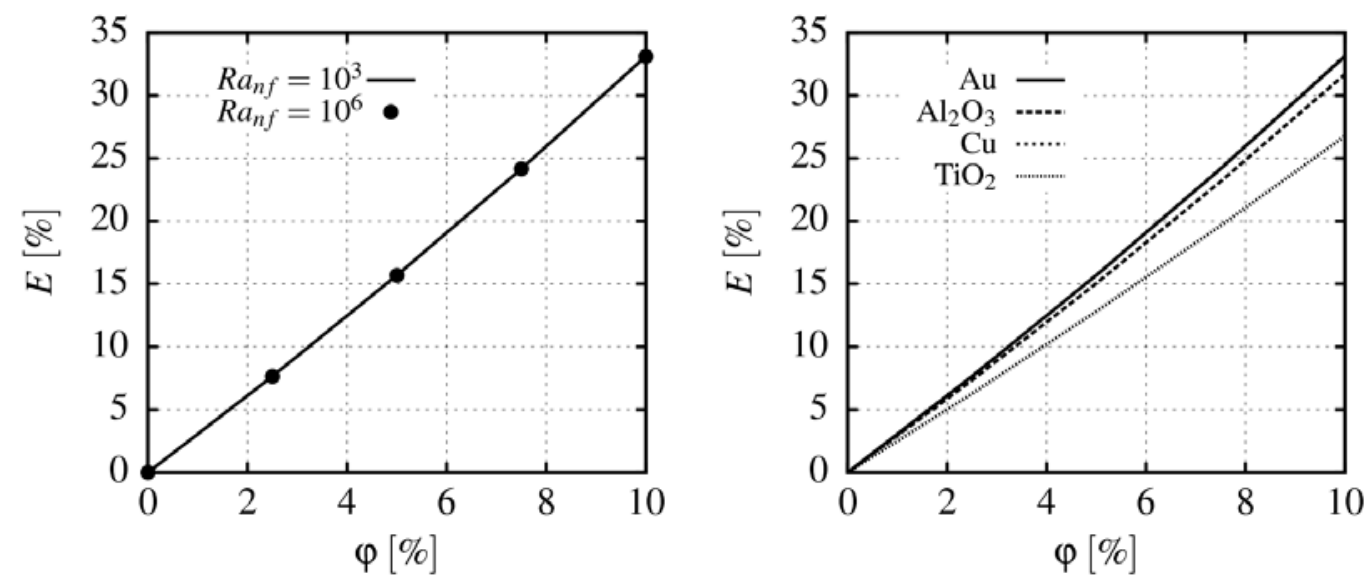

Figure 7: Enhancement of the heat transfer rate for CMC-Au nanofluid (left) and CMC-Au, $\mathrm{CMC}-\mathrm{Al}_{2} \mathrm{O}_{3}, \mathrm{CMC}-\mathrm{Cu}$ and $\mathrm{CMC}-\mathrm{TiO}_{2}$ nanofluids (right). 
At any given solid volume fraction $\varphi$ the heat transfer rate enhancement depends on the thermo-physical properties (i.e. the ratio of the nanofluid to the base fluid thermal conductivity $k_{n f} / k_{b f}$ ) of the nanoparticles (Fig. 7, right). Nanoparticles having the higher ratio $k_{n f} / k_{b f}$ (e.g. Au and $\mathrm{Cu}$ nanoparticles as shown in Fig. 8) yield greater enhancement of heat transfer rate.

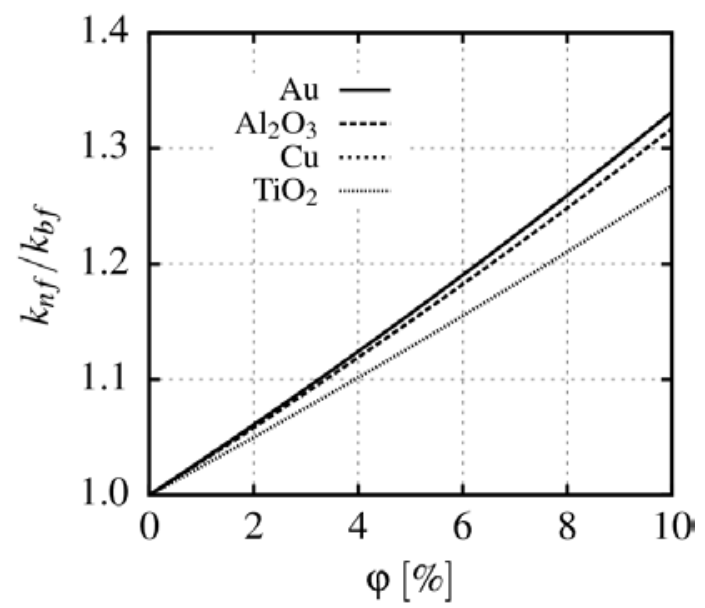

Figure 8: Ratio of the nanofluid to the base fluid thermal conductivity $k_{n f} / k_{b f}$.

\section{CONCLUSIONS}

In the present study, steady and laminar natural convection of non-Newtonian nanofluids in a square enclosure with differentially heated vertical walls have been studied by numerical means. The effects of nanofluid Rayleigh number $\left(10^{3} \leq R a_{n f} \leq 10^{6}\right)$ and solid volume fraction $(0 \% \leq \varphi \leq 10 \%)$ on heat and momentum transport have been systematically investigated.

The influence of computational grid refinement on the present numerical predictions was studied throughout the examination of grid convergence for CMC-Au nanofluid at $R a_{n f}=10^{5}$ and $\varphi=10 \%$. By utilizing extremely fine meshes the resulting discretisation error for the mean Nusselt number is below 0,3\%.

Numerical method was validated for the case of non-Newtonian Power-law fluid natural convection in a square cavity for which the results are available in the open literature. Remarkable agreement of present results with the benchmark results yields sufficient confidence in present numerical procedure and results.

Highly accurate numerical results released some important points such as:

- For a given set of values of solid volume fraction $\varphi$ an increase in the nanofluid Rayleigh number $R a_{n f}$ gives rise to strengthening of buoyancy forces in comparison to the viscous forces.

- Heat and momentum characteristics at given nanofluid Rayleigh number $R a_{n f}$ are independent of the volume fraction $\varphi$ and the type of nanoparticles.

- The mean Nusselt number $\overline{N u}$ monotonically increases with increasing nanofluid Rayleigh number $R a_{n f}$ but its variation (with $\varphi$ and $R a_{n f}$ ) is the same for all CMC-based nanofluids considered herein. In addition, changes in solid volume fraction $\varphi$ do not affect the value of $\overline{\mathrm{Nu}}$.

- Enhancement of the heat transfer rate $E$ increases with increasing solid volume fraction $\varphi$, but is practically unaffected by the value of nanofluid Rayleigh number $R a_{n f}$.

- Nanoparticles having the higher ratio $k_{n f} / k_{b f}$ yield greater enhancement of heat transfer rate. 


\section{ACKNOWLEDGEMENT}

The research leading to these results was carried out within the framework of a research project "Production technology of Au nano-particles" (L2-4212) and has received funding from the Slovenian Research Agency (ARRS).

\section{REFERENCES}

[1] Neslusan, M.; Mrkvica, I.; Cep, R.; Kozak, D.; Konderla, R. (2011). Deformations after heat treatment and their influence on cutting process, Technical Gazette, Vol. 18, No. 4, 601-608

[2] Ghosh, A.; Chattopadhyaya, S.; Hloch, S. (2012). Prediction of weld bead parameters, transient temperature distribution \& HAZ width of submerged arc welded structural steel plates, Technical Gazette, Vol. 19, No. 3, 617-620

[3] Brezocnik, M.; Buchmeister, B.; Gusel, L. (2011). Evolutionary algorithm approaches to modeling of flow stress, Materials and manufacturing processes, Vol. 26, No. 3, 501-507, doi:10.1080/10426914.2010.523914

[4] Choi, S. U. S. (1995). Enhancing thermal conductivity of fluids with nanoparticles, Siginer, D. A.; Wang, H. P. (Eds.), Developments Applications of Non-Newtonian Flows, FED-Vol. 231/MD-Vol. 66, ASME, New York, 99-105

[5] Rek, Z.; Rudolf, M.; Zun, Z. (2012). Application of CFD Simulation in the Development of a New Generation Heating Oven, Strojniski vestnik - Journal of Mechanical Engineering, Vol. 58, No. 2, 134-144, doi:10.5545/sv-jme.2011.163

[6] Venko, S.; Vidrih, B.; Pavlovic, E.; Medved, S. (2012). Enhanced Heat Transfer on Thermo Active Cooling Wall, Strojniski vestnik - Journal of Mechanical Engineering, Vol. 58, No. 11, 623-632, doi:10.5545/sv-jme.2012.436

[7] Stritih, U.; Butala, V. (2011). Energy Savings in Building with a PCM Free Cooling System, Strojniski vestnik - Journal of Mechanical Engineering, Vol. 57, No. 2, 125-134, doi:10.5545/svjme.2010.066

[8] Contuzzi, N.; Campanelli, S. L.; Ludovico, A. D. (2011). 3D finite element analysis in the selective laser melting process, International Journal of Simulation Modelling, Vol. 10, No. 3, 113-121, doi:10.2507/IJSIMM10(3)1.169

[9] De Vahl Davis, G. (1983) Natural convection of air in a square cavity: a bench mark numerical solution, International Journal for Numerical Methods in Fluids, Vol. 3, No. 3, 249-264, doi:10.1002/fld.1650030305

[10] Ternik, P.; Rudolf, R.; Zunic, Z. (2012). Numerical study of heat transfer enhancement of homogeneous water-Au nanofluid under natural convection, Materials and Technology, Vol. 46, No. 3, 257-261

[11] Ternik, P.; Rudolf, R. (2012). Heat transfer enhancement for natural convection flow of waterbased nanofluids in a square enclosure, International Journal of Simulation Modelling, Vol. 11, No. 1, 29-39, doi:10.2507/IJSIMM11(1)3.198

[12] Abu-Nada, E.; Oztop, H. F. (2009). Effects of inclination angle on natural convection in enclosures filled with Cu-water nanofluid, International Journal of Heat and Fluid Flow, Vol. 30, No. 4, 669-678, doi:10.1016/j.ijheatfluidflow.2009.02.001

[13] Oztop, H. F.; Abu-Nada, E.; Varol, Y.; Al-Salem, K. (2011). Computational analysis of nonisothermal temperature distribution on natural convection in nanofluid filled enclosures, Superlattices and Microstructures, Vol. 49, No. 4, 453-467, doi:10.1016/j.spmi.2011.01.002

[14] Mahrood, M. R. K.; Etemad, S. G.; Bagheri, R. (2011). Free convection heat transfer of non Newtonian nanofluids under constant heat flux condition, International Communications in Heat and Mass Transfer, Vol. 38, No. 10, 1449-1454, doi:10.1016/j.icheatmasstransfer.2011.08.012

[15] Cheng, C.-Y. (2012). Free convection of non-Newtonian nanofluids about a vertical truncated cone in a porous medium, International Communications in Heat and Mass Transfer, Vol. 39, No. 9, 1348-1353, doi:10.1016/j.icheatmasstransfer.2012.08.004

[16] Moraveji, M. K.; Haddad, S. M. H.; Darabi, M. (2012). Modeling of forced convective heat transfer of a non-Newtonian nanofluid in the horizontal tube under constant heat flux with 
computational fluid dynamics, International Communications in Heat and Mass Transfer, Vol. 39, No. 7, 995-999, doi:10.1016/j.icheatmasstransfer.2011.05.003

[17] Bilus, I.; Ternik, P.; Zunic, Z. (2011). Further contributions on the flow past a stationary and confined cylinder: Creeping and slowly moving flow of Power law fluids, Journal of Fluids and Structures, Vol. 27, No. 7, 1278-1295, doi:10.1016/j.jfluidstructs.2011.06.004

[18] Turan, O.; Sachdeva, A.; Chakraborty, N.; Poole, R. J. (2011). Laminar natural convection of power-law fluids in a square enclosure with differentially heated side walls subjected to constant temperatures, Journal of Non-Newtonian Fluid Mechanics, Vol. 166, No. 17-18, 1049-1063, doi:10.1016/j.jnnfm.2011.06.003

[19] Turan, O.; Sachdeva, A.; Poole, R. J.; Chakraborty, N. (2012). Laminar Natural Convection of Power-Law Fluids in a Square Enclosure With Differentially Heated Sidewalls Subjected to Constant Wall Heat Flux, Journal of Heat Transfer, Vol. 134, No. 12, 122504/1-15, doi:10.1115/1.4007123

[20] Roache, P. J. (1994). Perspective: A method for uniform reporting of grid refinement studies, Journal of Fluids Engineering, Vol. 116, No. 3, 405-413, doi:10.1115/1.2910291 